\title{
Early parenteral nutrition progression and nutritional parameters in critically ill patients
}

\author{
Progressão da nutrição parenteral precoce e parâmetros nutricionais em pacientes gravemente \\ enfermos
}

DOI: $10.37111 /$ braspenj.2020353010

Letícia Sabino Santos ${ }^{\top}$

Karla Mendonça Gonçalves de Jesus'

Marcia Regina Dantas de Araújo Oliveira ${ }^{2}$

Mariana Câmara Martins Bezerra Furtado ${ }^{3}$

Karina Marques Vermeulen-Serpa ${ }^{4}$

Sancha Helena de Lima Vale ${ }^{5}$

Márcia Marília Gomes Dantas Lopes

Lucia Leite-Lais ${ }^{6}$

\section{Unitermos:}

Cuidados críticos. Avaliação nutricional. Nutrição parenteral. Prognóstico.

\section{Keywords:}

Critical care. Nutrition assessment. Parenteral nutrition. Prognosis.

\section{Corresponding author:}

Márcia Marília Gomes Dantas Lopes

Federal University of Rio Grande do Norte, Department of Nutrition

Av. Senador Salgado Filho, 3000 - Lagoa Nova -

Natal, RN, Brazil - Zip code: 59078-970

E-mail: mariliagdantas@hotmail.com

\section{Submission:}

June 2, 2020

\section{Accepted for publication}

September 8, 2020

\begin{abstract}
Introduction: Parenteral nutrition (PN) could be a life-sustaining therapy for patients unable to achieve their nutritional needs by oral intake and/or enteral nutrition. This study is aimed to evaluate PN progression in the first 3 days $(72 \mathrm{~h}$ ) of critically ill patients admitted to an intensive care unit (ICU) and to verify some of their nutritional parameters. Methods: In this observational prospective cohort study, we performed nutritional screening and evaluation of critically ill patients receiving early PN using the following parameters: NUTRIC Score, adductor pollicis muscle thickness (APMT), phase angle (PA), and standardized phase angle (SPA). In addition, PN adequacy was evaluated during the first 3 days, following the literature recommendations. Results: Twelve patients were enrolled in this study. Among them, 58\% were female and $75 \%$ were more than 60 years of age. Most of them had cancer and had surgical treatment. PN was recommended due to intestinal obstruction (50\%), gastroparesis (33\%), and gastrointestinal fistulas (17\%). Before PN therapy started, the fasting period was approximately 3 days. Almost all patients had high nutritional risk and poor nutritional status and prognosis. This study showed that progressive energy and protein targets were not reached in the first 3 days (72 hours) in most patients with exclusive PN therapy. Conclusions: The participants of this study presented a high nutritional risk, mild malnutrition, and poor prognosis. Most of these patients did not meet the goal of their nutritional requirements within 72 hours after initiation of $\mathrm{PN}$ therapy. outcome.
\end{abstract}

\section{RESUMO}

Introdução: A nutrição parenteral (NP) pode assegurar a vida de pacientes incapazes de atingir suas necessidades nutricionais via oral ou enteral. Este estudo teve como objetivo avaliar a progressão da NP nos primeiros 3 dias $(72 \mathrm{~h}$ ), em pacientes críticos admitidos em unidade de terapia intensiva (UTI) e verificar alguns de seus parâmetros nutricionais. Método: Neste estudo de coorte prospectivo observacional, foi realizada triagem e avaliação nutricional dos pacientes críticos recebendo NP precoce, usando os seguintes parâmetros: NUTRIC Score, espessura do músculo adutor do polegar (APMT), ângulo de fase (PA) e ângulo de fase padronizado (SPA). Além disso, avaliamos a adequação da NP durante os primeiros 3 dias, seguindo as recomendações da literatura. Resultados: Doze pacientes foram incluídos no estudo. Entre eles, $58 \%$ eram do sexo feminino e $75 \%$ tinham 60 anos ou mais. A maioria apresentava câncer e tinha sido submetida a tratamento cirúrgico. A NP foi recomendada devido a obstrução intestinal (50\%), gastroparesia $(33 \%)$ e fístulas gastrointestinais (17\%). Antes do início da NP, o período médio de jejum foi 3 dias. Quase todos os pacientes apresentaram elevado risco nutricional, estado nutricional e prognóstico desfavoráveis. Este estudo demonstrou que as metas progressivas de energia e proteína não foram atingidas nos primeiros 3 dias (72 horas) na maioria dos pacientes com NP exclusiva. Conclusões: Os participantes deste estudo apresentavam alto risco nutricional, desnutrição leve e mau prognóstico. A maioria desses pacientes não atingiu a meta de suas necessidades nutricionais dentro de 72 horas após o início da terapia de NP. Além disso, não foi observada uma uniformidade da progressão da PN.

1. Nutricionista Especialista. Universidade Federal do Rio Grande do Norte. Hospital Universitário Onofre Lopes, Programa de Residência Integrada Multiprofissional em Saúde, Terapia Intensiva Adulto. Natal, RN, Brasil.

2. Nutricionista. Universidade Federal do Rio Grande do Norte. Hospital Universitário Onofre Lopes. Natal, RN, Brasil.

3. Nutricionista Mestre. Universidade Federal do Rio Grande do Norte. Hospital Universitário Onofre Lopes. Natal, RN, Brasil.

4. Nutricionista Mestre. Universidade Federal do Rio Grande do Norte. Programa de Pós graduação em Ciências da Saúde. Natal, RN, Brasil.

5 Nutricionista Doutora. Universidade Federal do Rio Grande do Norte. Centro de Ciências da Saúde, Departamento de Nutrição. Natal, RN, Brasil.

6 Nutricionista Pós Doutora. Universidade Federal do Rio Grande do Norte. Centro de Ciências da Saúde, Departamento de Nutrição. Natal, RN, Brasil. 


\section{INTRODUCTION}

Intensive care unit (ICU) is a hospital area that provides intensive and continuous medical assistance to critically ill patients. Critically ill patients are often under catabolic stress associated with systemic inflammatory response, which leads to increased risk of infections, multiple-organ dysfunction, prolonged hospitalization, and high mortality'. Acute stress interferes with neuroendocrine and immune systems. Consequently, high levels of pro-inflammatory cytokines, hyperglycemia, insulin resistance, lipolysis, and protein catabolism are common responses to subjacent acute illness and directly affect the nutritional status. In addition, muscle wasting occurs early and rapidly during the first week of critical illness 2 .

Since nutrition status directly influences patients' outcome in ICU, nutritional screening and evaluation of critically ill patients are of utmost importance. Despite challenges in screening and evaluation of the nutritional status in these patients, some tools and parameters have been used for this purpose, such as NUTRIC Score ${ }^{3,4}$, adductor pollicis muscle thickness (APMT) ${ }^{5}$ and phase angle (PA) ${ }^{6}$.

Early and adequate nutritional support is an essential part of optimal medical care for critically ill patients. It improves nutritional status, attenuates disease severity, diminishes complications, improves wound healing, decreases the length of stay in ICU, reduces mechanical ventilation dependency, and positively impacts patients' outcome ${ }^{1,7}$.

Parenteral nutrition (PN) therapy is the intravenous administration of nutrients through a sterile and apyrogenic solution or emulsion, consisting of amino acids, glucose, lipid, electrolytes, trace elements, and vitamins. PN admixtures can be two-in-one or all-in-one, depending on the presence or absence of lipids. It can be a life-sustaining therapy providing nutrients to malnourished patients (or not) unable to achieve their nutritional needs by oral intake and/or enteral nutrition ${ }^{8}$.

Energy and protein adequacy of patients under PN therapy is important to minimize the risk of malnutrition or avoid its worsening. The nutrition team must ensure that patients are reaching their nutritional needs, especially for energy and protein intended by the PN prescribed ${ }^{2}$. Unfortunately, metabolic, mechanical, and infectious complications in critically ill patients can delay PN initiation or its progression and impair their nutritional status.

The European Society for Clinical Nutrition and Metabolism (ESPEN) states that, in the case of contraindications to oral and enteral nutrition, PN should be implemented within 3-7 days $^{7}$. For some authors, PN goals can be achieved in 2-3 days in most adult patients? 9 . More recently, authors have suggested a slow progression of PN in the first 3 days, but still achieving targets of energy and protein in the early phase $^{10}$. Early progressive feeding could avoid the worsening of patients' nutritional status, but if it is not well planned, could pose complications related to overfeeding.

Despite the importance of an early PN therapy, most of the studies about PN adequacy takes into consideration a longer period of time (goals achieved within 7 days). Considering the scarcity of studies about early parenteral nutrition progression, this study aimed to evaluate $\mathrm{PN}$ progression in the first 3 days (72 $\mathrm{h}$ ) in critically ill patients admitted in an ICU and to verify some of their nutritional parameters as well.

\section{METHODS}

\section{Study Design, Ethical Aspects, and Participants}

This observational prospective cohort study was reviewed and approved by the Ethics Committee of the Onofre Lopes University Hospital in Natal, Brazil (CAAE: 611061 16.5.0000.5292). It was conducted according to the Resolution 466/12 of Brazil's National Health Council. All subjects or their legal guardians provided written, informed consent before enrollment.

This study was conducted with all patients, 18 years or older, admitted in the ICU of the Onofre Lopes University Hospital, between September 2017 and October 2018, and initiating and receiving exclusive PN therapy for at least 3 days. Patients with a shorter length of stay (LOS) in ICU and those not indicated for bioimpedance evaluation (pregnant women, amputees, and pacemaker users) were excluded.

\section{Data Collection}

All medical record data was collected by a registered dietitian, part of the multidisciplinary ICU team. The data was comprised of medical diagnosis, feeding route, nutritional requirements, composition, and volume administered of $\mathrm{PN}$, LOS, and outcome.

\section{PN Adequacy}

PN adequacy of the participants was based on recent recommendations for the early phase of critical illness. Energy and protein requirements were $25 \mathrm{kcal} / \mathrm{kg} /$ day and $1.3 \mathrm{~g} /$ $\mathrm{kg} /$ day, respectively ${ }^{7}$. The goal was delivering hypocaloric nutrition (up to $70 \%$ of the energy expenditure) ${ }^{7}$, with gradual progression of energy and protein targets: $25 \%$ (day 1), $50 \%$ (day 2), $75 \%$ (day 3$)^{10}$. Considering that, the first 3 days of PN adequacy were calculated by the percentage of the targets of energy and protein achieved per day by each patient.

\section{Nutritional Screening and Evaluation}

The nutritional screening was performed by NUTRIC Score and the nutritional evaluation by APMT and PA. The NUTRIC Score is a tool developed and validated specifically for ICU patients aiming to identify patients at nutritional risk ${ }^{11}$. Originally, the tool includes 6 variables (age, APACHE II, SOFA, number of co-morbidities, days from hospital to ICU admission, and (L-6), but in this study, we used the adapted NUTRIC Score scoring system when IL-6 is not available ${ }^{12}$. According to this scoring system, the classification of low or high risk can be set when the sum of points is $0-4$ or $5-9$, respectively. 
The low score indicates patients with a low malnutrition risk. The variables used to calculate de NUTRIC Score were collected from the patients' medical records, including the APACHE II (Acute Physiology and Chronic Health Evaluation II) and SOFA (Sequential Organ Failure Assessment) which are disease severity scores.

In our study, the APMT of the participants was measured according to Lameu et al. ${ }^{13}$. PA was obtained by bioimpedance (BIA). We used a Quantum IV Bioelectric Impedance Analyzer (RJL Systems, Clinton Township, MI, USA), which promoted the passage of a safe and painless low-frequency current $(50 \mathrm{kHz}, 800 \mu \mathrm{A})$, following the instructions previously described ${ }^{14}$. Having resistance $(R)$ and reactance $\left(X_{C}\right)$ by BIA, it was possible to calculate the PA using the following equation: $\mathrm{PA}=$ arc-tangent $\left(\mathrm{XC}_{\mathrm{C}} / \mathrm{R}\right) \times 180 / \pi$. In addition, the standardized PA (SPA) was calculated, via the following equation: SPA = [(measured PA - mean PA of the reference population)/standard deviation PA of the reference population]. Mean and standard deviation PA were from sex-, age-, and BMI-stratified reference values from a healthy population ${ }^{15}$. SPA values < $-1.65^{\circ}$ and $\geq-1.65^{\circ}$ were considered reduced and normal values, respectively $y^{6,15}$.

\section{Data Analysis}

The Shapiro-Wilk test was applied to verify the normality of data. Descriptive analysis was performed using measures of central tendency and dispersion, according to data type. The quantitative variables of normal distribution were expressed as means and standard deviations. Those with non-normal distribution were presented as median and interquartile range. Statistical analysis was performed with SPSS v.23 (SPSS Inc., Chicago, Illinois, USA).

\section{RESULTS}

The sample was comprised of 12 patients that were initiating exclusive PN therapy. Among them, 58\% were female and $75 \%$ were elderly (aged $\geq 60$ years). Surgical and clinical treatments were observed in $42 \%$ and $58 \%$ of the patients, respectively. The main medical diagnosis was cancer, found in $75 \%$ of the patients. PN was recommended due to intestinal obstruction (50\%), gastroparesis (33\%), and gastrointestinal fistulas (17\%). Before PN therapy started, the fasting period was approximately 3 days. Nutritional screening and evaluation results are described in Table 1.

Almost all patients had high nutritional risk. Median AMPT values for both men and women were within normal range. Mean PA and median SPA showed nutritional impairment and poor nutritional prognosis, since their values were very low. PN progression and adequacy of energy and protein are shown in Figures 1 and 2.

Table 1 - Characteristics and nutritional profile of critically ill patients initiating exclusive parenteral nutrition therapy.

\begin{tabular}{|c|c|}
\hline Parameters & Values \\
\hline \multicolumn{2}{|l|}{ Gender, n (\%) } \\
\hline Male & $5(42)$ \\
\hline Female & $7(58)$ \\
\hline Age (years) $^{a}$ & $62.50(17.23)$ \\
\hline \multicolumn{2}{|c|}{ Treatment, n (\%) } \\
\hline Medical & $5(42)$ \\
\hline Surgical & $7(58)$ \\
\hline Fasting (days) ${ }^{\mathrm{a}}$ & $3.58(2.99)$ \\
\hline \multicolumn{2}{|c|}{ NUTRIC Score, n (\%) } \\
\hline$\geq 5$ & $11(92)$ \\
\hline$\leq 4$ & $1(8)$ \\
\hline \multicolumn{2}{|l|}{ APMT $(\mathrm{mm})^{\mathrm{b}}$} \\
\hline Female & $13.0(11.0 ; 14.50)$ \\
\hline Male & $13.0(12.0 ; 16.00)$ \\
\hline $\mathrm{PA}\left({ }^{\circ}\right)^{\mathrm{a}}$ & $3.98(1.10)$ \\
\hline SPA $\left({ }^{\circ}\right)^{b}$ & $-2.77(-4.01 ;-1.64)$ \\
\hline
\end{tabular}

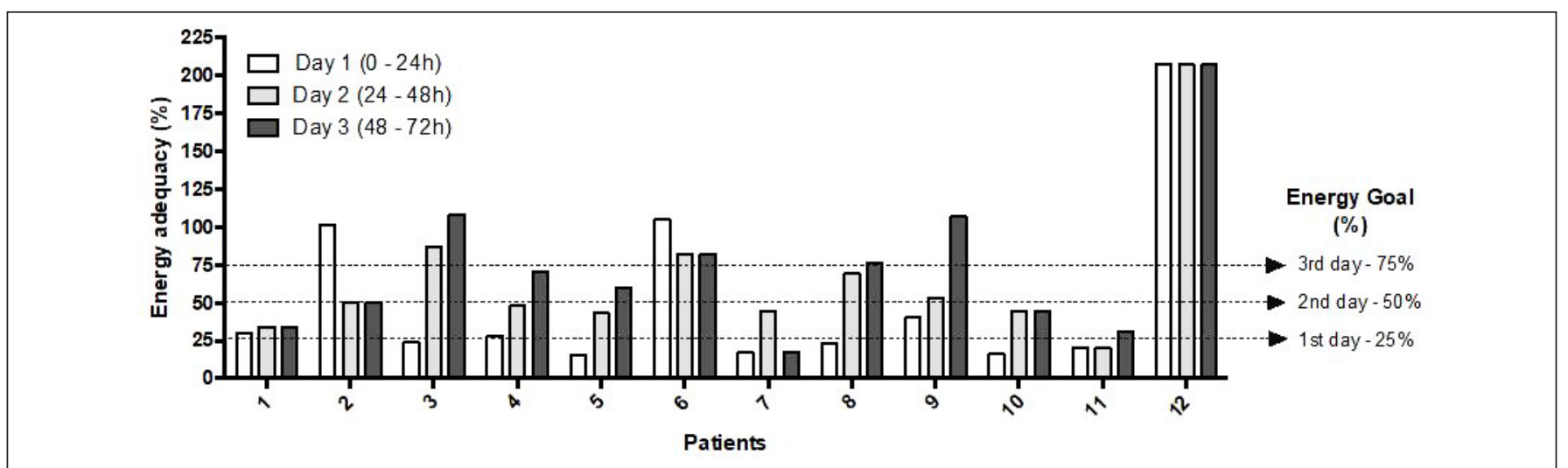

Figure 1 - Energy adequacy progression of exclusive parenteral nutrition therapy in critically ill patients during the first 3 days. It was observed that 3 patients reached 25\% of their energy goal on Day 1; 8 patients reached $50 \%$ of their energy goal on Day 2; and 5 patients reached their energy goal on Day 3. Moreover, it was noticed that the progression of PN was too quick in some patients (3, 6 and 8$)$ or too slow in others (1, 7, 10 and 11). Also, there was a case of overfeeding in patients 2 and 12. Particularly, patient 2 was overfed on Day 1 and the PN infusion had to be reduced the next 2 days. 


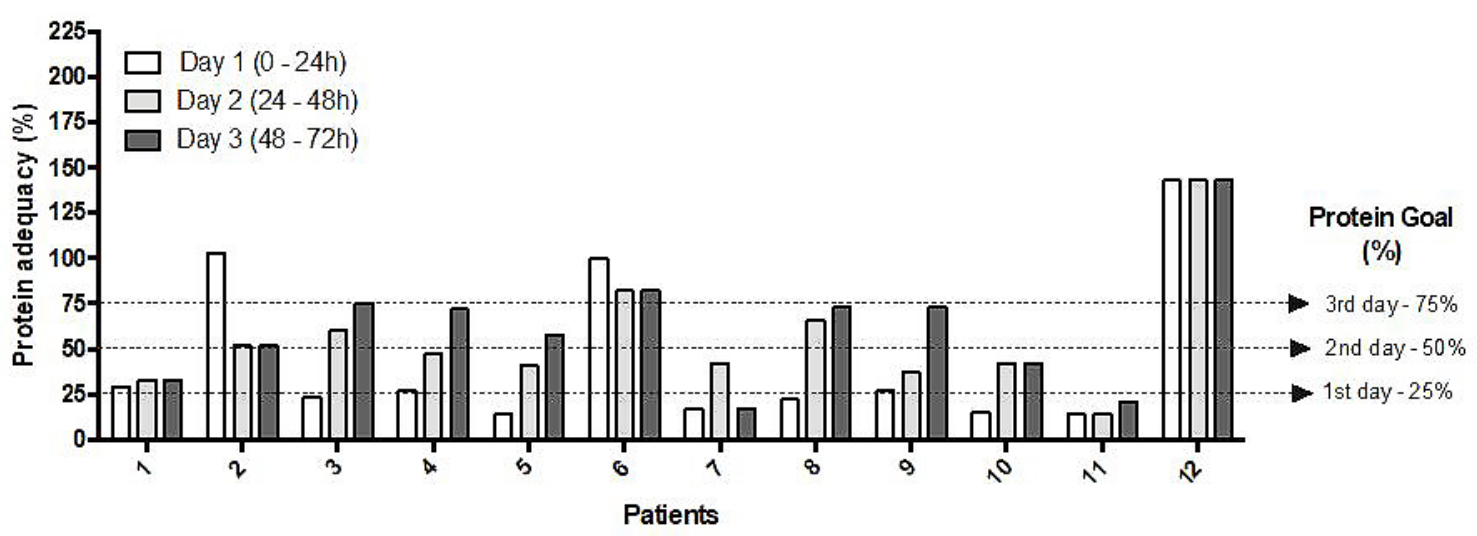

Figure 2 - Protein adequacy progression of exclusive parenteral nutrition therapy in critically ill patients during the first 3 days. It was observed that 3 patients reached 25\% of their protein goal on Day 1; 5 patients reached 50\% of their protein goal on Day 2; and 3 patients reached their protein goal on Day 3. A couple of patients were very close to their goals. Again, overfeeding took place in patient 2 (Day 1) and patient 12 (all 3 Days).

\section{DISCUSSION}

Our critically ill patients from both genders were predominantly old, surgical, and were facing a mean of 3 days of fasting before starting PN therapy. In ICU it is common to fast for diagnostic procedures, surgery, and airway management. However, these interruptions result in energy and protein deficits, impairing nutritional status and leading to increased complications. Protocols to reduce fasting time are advisable ${ }^{16}$. Medical nutrition therapy must be considered for all patients staying in ICU for more than $48 \mathrm{~h}$, but obviously respecting if there are contraindications ${ }^{7}$.

According to the NUTRIC Score, our population showed high nutritional risk. This result is associated with worse clinical outcomes and point to patients who will benefit the most from aggressive nutritional therapy, as elucidated in another study ${ }^{1}$.

Although there is still no defined APMT cutoff point for all populations, the APMT estimate for healthy men and women is $12.5 \mathrm{~mm}$ and $10.5 \mathrm{~mm}$, respectively ${ }^{17}$. As the adductor pollicis muscle is also consumed during catabolism and atrophied by inactivity ${ }^{17}$, it has been considered a good anthropometric parameter to evaluate muscle loss and malnutrition in most clinical conditions, including hospitalized patients ${ }^{18}$. In this study, median APMT (13 mm) observed (Table 1) was superior to the values proposed for healthy individuals ${ }^{17}$. However, compared to other studies performed with ICU patients, we found some with lower (around 7 and $8 \mathrm{~mm}^{19}$ ) and higher values (around 13 and $14 \mathrm{~mm}^{20}$, or $15 \mathrm{~mm}^{21}$ ). Lower APMT values can be found in the older population due to their physiological loss of lean mass ${ }^{19}$. APMT in dominant and non-dominant hands may differ, and the presence of edema may falsely increase its measurement. Despite these details, APMT is useful for clinical and prognosis purposes. Abnormal APMT values increase the LOS for approximately 5 days in patients without edema ${ }^{18}$. Each $1 \mathrm{~mm}$ decrease in APMT can increase the risk of death by $38 \%$ in ICU patients ${ }^{21}$.
Although there is no definitive cutoff point of PA for critically ill patients, some authors suggest that PA values $\leq$ $5.1^{\circ}$ predicts severity of the critical illness, $\leq 5.5^{\circ}$ predicts high nutritional risk, $<2^{\circ}$ suggests severe malnutrition, $2-3^{\circ}$ suggests moderate malnutrition, and $>3^{\circ}$ suggests mild malnutrition ${ }^{4,22}$. In this study, a lower mean PA (3.98०) was found compared to other studies $\left(5.34^{\circ} \text { and } 5.4^{\circ}\right)^{6,22}$ performed on critically ill patients. However, Yao et al. ${ }^{23}$ found similar PA values $\left(3.6^{\circ}\right)$ to ours. According to Razzera et al. ${ }^{22}$, a PA $<5.5^{\circ}$ was associated with mortality and prolonged ICU LOS. In the study of do Amaral Paes et al. ${ }^{24}$, patients with a $\mathrm{PA} \leq 3.8^{\circ}$ had a shorter survival time than those with a PA $>3.8^{\circ}$. As PA may differ between men and women and/or adults and elderly patients, SPA should be used. In this study, median SPA was $-2.77^{\circ}$. This result was lower compared to other studies mentioned previously $\left(-1.51^{\circ} \text { and }-1.1^{\circ}\right)^{6,22}$ and it was classified as low SPA 6 , 15 . Reduced SPA increases the chance of malnutrition and LOS in critically ill patients ${ }^{6}$. Low PA and SPA found in our patients are related to the severity of their clinical condition and point to the high nutritional risk and poor patients' outcomes. These parameters may be helpful during the nutritional evaluation of ICU patients. They are low cost and seem to be effective in predicting malnutrition and identifying worse clinical prognosis. Another advantage is that PA can detect body composition changes even before anthropometric changes can be detected ${ }^{25}$.

Progression of $\mathrm{PN}$ therapy during the acute phase is important to avoid overfeeding and still ensure nutritional support that is needed for patient recovery ${ }^{10}$. Energy and protein targets should not be considered separately but integrated into a more comprehensive approach, considering timing and route of nutrition therapy'. Thus, timing matters and may be a decisive factor to positively or negatively influence nutritional status of critically ill patients. 
This study showed that energy and protein targets were not reached in the first 3 days (72 hours) in most patients with exclusive PN therapy. Provision of adequate energy and protein is of utmost importance in preserving lean mass, contributing to proper neuro-endocrine and immune responses, and minimizing the risk of infections, multipleorgan dysfunction, prolonged hospitalization, and mortality. Clinical observations suggest that proper provision of protein is as important as energy provision ${ }^{26}$.

In this study, PN implementation occurred within 3 days and it was in consonance with ESPEN that recommends 3 to 7 days $^{7}$. However, progression of PN was insufficient in many patients. Conditions such as metabolic/hemodynamic instability and airway manipulation could have hindered progression of PN in these patients. Moreover, quick or slow progression of $\mathrm{PN}$ among patients and possible overfeeding in other patients (Figures 1 and 2) may suggest the absence of a specific protocol for PN progression in ICU.

The absence or nonuniformity of nutritional protocols to guide practice in ICU patients may result in inadequacy in delivering nutritional support, increased morbidity, prolonged LOS, higher costs, and increased mortality ${ }^{27}$. Development of PN protocols are helpful to achieve energy and protein targets. Nutritional guidelines and adapted local protocols are helpful in standardizing and improving the quality of this therapy in ICU and must be developed and followed ${ }^{28}$.

The limitations of this study were the small number of patients receiving exclusive $\mathrm{PN}$, small number of beds in the hospital, and few studies addressing this same subject.

\section{CONCLUSION}

The participants of this study presented a high nutritional risk, mild malnutrition, and poor prognosis. Most of these patients did not meet the goal of their nutritional requirements within 72 hours after initiation of PN therapy. Also, a nonuniformity of PN progression was observed. Inadequacy of nutritional therapy can negatively impact a patients' outcome. Development of local protocols based on parenteral nutrition guidelines and continuing education of the EMTN may be relevant measures to ensure PN adequacy and promote a better response of critically ill patients towards their clinical treatment.

\section{REFERENCES}

1. McClave SA, Taylor BE, Martindale RG, Warren MM, Johnson DR, Braunschweig C, et al; Society of Critical Care Medicine; American Society for Parenteral and Enteral Nutrition. Guidelines for the provision and assessment of nutrition support therapy in the adult critically ill patient: Society of Critical Care Medicine (SCCM) and American Society for Parenteral and Enteral Nutrition (A.S.P.E.N.). JPEN J Parenter Enteral Nutr. 2016;40(2):159-211.
2. Puthucheary ZA, Rawal J, McPhail M, Connolly B, Ratnayake $\mathrm{G}$, Chan P, et al. Acute skeletal muscle wasting in critical illness. JAMA. 2013;310(15):1591-600.

3. Heyland DK, Dhaliwal R, Wang M, Day AG. The prevalence of iatrogenic underfeeding in the nutritionally 'at-risk' critically ill patient: results of an international, multicenter, prospective study. Clin Nutr. 2015;34(4):659-66.

4. Al-Kalaldeh M, Suleiman K, Al-Kalaldeh O. Prognostic performance of NUTRIC score in quantifying malnutrition risk in the critically ill in congruence with the bioelectrical impedance analysis. Nutr Clin Pract. 2020;35(3):559-66.

5. Pereira TG, Silva Fink J, Silva FM. Thickness of the adductor pollicis muscle: accuracy in predicting malnutrition and length of intensive care unit stay in critically ill surgical patients. Thickness of the adductor pollicis muscle in surgical critically patients. Clin Nutr ESPEN. 2018;24:165-9.

6. Jansen AK, Gattermann T, Silva Fink J, Saldanha MF, Dias Nascimento Rocha C, Souza Moreira T, et al. Low standardized phase angle predicts prolonged hospitalization in critically ill patients. Clin Nutr ESPEN. 2019;34:68-72.

7. Singer P, BlaserAR, Berger MM, Alhazzani W, Calder PC, Casaer MP, et al. ESPEN guideline on clinical nutrition in the intensive care unit. Clin Nutr. 2019;38(1):48-79.

8. Barnett MI, Pertkiewicz M, Cosslett AG, Muhlebach S. Basics in clinical nutrition: parenteral nutrition admixtures, how to prepare parenteral nutrition $(\mathrm{PN})$ admixtures. e-SPEN. 2009;4(3):e114-6.

9. Derenski K, Catlin J, Allen L. Parenteral nutrition basics for the clinician caring for the adult patient. Nutr Clin Pract. 2016;31(5):578-95.

10. van Zanten ARH, Waele E, Wischmeyer PE. Nutrition therapy and critical illness: practical guidance for the ICU, post-ICU, and long-term convalescence phases. Crit Care. 2019;23(1):368.

11. Heyland DK, Dhaliwal R, Jiang X, Day AG. Identifying critically ill patients who benefit the most from nutrition therapy: the development and initial validation of a novel risk assessment tool. Crit Care. 2011;15(6):R268.

12. Rahman A, Hasan RM, Agarwala R, Martin C, Day AG, Heyland DK. Identifying critically-ill patients who will benefit most from nutritional therapy: further validation of the "modified NUTRIC" nutritional risk assessment tool. Clin Nutr. 2016;35(1):158-62.

13. Lameu EB, Gerude MF, Campos AC, Luiz RR. The thickness of the adductor pollicis muscle reflects the muscle compartment and may be used as a new anthropometric parameter for nutritional assessment. Curr Opin Clin Nutr Metab Care. 2004;7(3):293-301.

14. National Institutes of Health Technology Assessment Conference Statement. Bioelectrical impedance analysis in body composition measurement: National Institutes of Health Technology Assessment Conference Statement. Am J Clin Nutr. 1996;64(3 Suppl):524S-32S.

15. Barbosa-Silva MC, Barros AJ, Wang J, Heymsfield SB, Pierson RN Jr. Bioelectrical impedance analysis: population reference values for phase angle by age and sex. Am J Clin Nutr. 2005;82(1):49-52.

16. Segaran E, Barker I, Hartle A. Optimizing enteral nutrition in critically ill patients by reducing fasting times. J Intensive Care Soc. 2016;17(1):38-43.

17. Lameu EB, Gerude MF, Corrêa RC, Lima KA. Adductor pollicis muscle: a new anthropometric parameter. Rev Hosp Clin Fac Med Sao Paulo. 2004;59(2):57-62.

18. Soares BGFDS, Vicentini AP. Use of adductor pollicis muscle thickness in hospitalized or ambulatory patients: a systematic review. Rev Lat Am Enfermagem. 2018;26:e2960.

19. Karst FP, Vieira RM, Barbiero S. Relationship between adductor pollicis muscle thickness and subjective global assessment in a cardiac intensive care unit. Rev Bras Ter Intensiva. 2015;27(4):369-75. 
20. Ghorabi S, Ardehali H, Amiri Z, Vahdat Shariatpanahi Z. Association of the adductor pollicis muscle thickness with clinical outcomes in intensive care unit patients. Nutr Clin Pract. 2016;31(4):523-6.

21. Nematifard E, Ardehali SH, Shahbazi S, Eini-Zinab H, Vahdat Shariatpanahi Z. Combination of APACHE scoring systems with adductor pollicis muscle thickness for the prediction of mortality in patients who spend more than one day in the intensive care unit. Crit Care Res Pract. 2018;2018:5490346.

22. Razzera EL, Marcadenti A, Rovedder SW, Alves FD, Fink JDS, Silva FM. Parameters of bioelectrical impedance are good predictors of nutrition risk, length of stay, and mortality in critically ill patients: a prospective cohort study. JPEN J Parenter Enteral Nutr. 2019;44(5):849-54.

23. Yao J, Zhou M, Xu B, Li C, Chen H, Gong D. The association of bioimpedance analysis parameters with the outcomes of critically ill patients. Clin Nutr. 2019;S0261-5614(19)33204-2.

24. Amaral Paes TC, Oliveira KCC, Carvalho Padilha P, Peres WAF. Phase angle assessment in critically ill cancer patients:
Relationship with the nutritional status, prognostic factors and death. J Crit Care. 2018;44:430-5.

25. Vermeulen KM, Lopes MMGD, Grilo EC, Alves CX, Machado RJA, Lais LL, et al. Bioelectrical impedance vector analysis and phase angle in boys with Duchenne muscular dystrophy. Food Nutr Res. 2019;63.

26. Alberda C, Gramlich L, Jones N, Jeejeebhoy K, Day AG, Dhaliwal $\mathrm{R}$, et al. The relationship between nutritional intake and clinical outcomes in critically ill patients: results of an international multicenter observational study. Intensive Care Med. 2009;35(10):1728-37.

27. Mehta Y, Sunavala JD, Zirpe K, Tyagi N, Garg S, Sinha S, et al. Practice guidelines for nutrition in critically ill patients: a relook for Indian scenario. Indian J Crit Care Med. 2018;22(4):263-73.

28. Kopp Lugli A, Watteville A, Hollinger A, Goetz N, Heidegger C. Medical nutrition therapy in critically ill patients treated on intensive and intermediate care units: a literature review. J Clin Med. 2019;8(9):1395.

Institution where the study was developed: University Hospital Onofre Lopes, Federal University of Rio Grande do Norte, Natal, RN, Brazil.

Conflict of interest: The authors declare that they have no conflicts of interest. 